COMMENTARY

\title{
Should we treat all subjects with subclinical thyroid disease the same way?
}

\author{
Bernadette Biondi \\ Department of Clinical and Molecular Endocrinology and Oncology, University of Naples Federico II, Via S. Pansini 5, 80131 Naples, Italy \\ (Correspondence should be addressed to B Biondi; Email: bebiondi@unina.it)
}

Overt hypothyroidism and hyperthyroidism are associated with an increased cardiovascular risk (1). Despite the high prevalence of subclinical thyroid disease and the potential progression to overt disease, the risk associated with this condition is debated $(2,3)$. The potential cardiovascular risk in subclinical thyroid disease is an important factor that can affect decisions about the screening and treatment of patients $(4,5)$.

Alterations of cardiovascular function have been reported in young and middle-aged individuals with persistent subclinical hyperthyroidism (SHyper) $(4,5)$. Moreover, the atherosclerotic risk was found to be higher in SHyper patients with decreased serum thyrotrophin (TSH) levels (6). In elderly individuals, SHyper is associated with an increased prevalence of atrial fibrillation, and the hypercoagulable state could predispose these subjects to an increased thromboembolic risk (7). SHyper has been linked to several important independent cardiovascular risk factors, and if left untreated could, in the long term, increase morbidity and mortality due to coronary heart disease, stroke, heart failure, and sudden death, especially in the elderly.

Three studies have assessed cardiovascular mortality in patients with endogenous SHyper (7-9). No adverse outcome and no increased cardiovascular mortality was observed by Cappola et al. (7) and Walsh et al. (9) in patients with endogenous SHyper as a whole, or in the subgroup with serum TSH less than $0.1 \mathrm{mIU} / \mathrm{l}$ and serum TSH between 0.1 and $0.4 \mathrm{mIU} / \mathrm{l}$. On the contrary, in another study, survival was poorest in subjects with low serum TSH $(<0.5 \mathrm{mIU} / \mathrm{l})(8)$, and there was no difference in survival between patients with a low but detectable TSH and undetectable serum TSH. The increased mortality was due to cardiovascular diseases. Interestingly, thyroid hormone use was not related to cardiovascular mortality among women with baseline TSH below the normal range in the community dwelling study by Bauer et al. (10).

The epidemiological studies of endogenous SHyper have several limitations, subclinical thyroid dysfunction may not be stable over time and not all studies provided information about: 1) the pre-diagnosis duration of SHyper; 2) the diagnosis of SHyper; and 3) the progression or treatment of thyroid dysfunction of the members of some cohorts. Lastly, the analysis was not always adjusted for associated cardiovascular risk factors.
Several recent meta-analyses $(11,12)$ have examined the cardiovascular risk associated with SHyper with the aim of establishing whether treatment should be considered in young and middle-aged patients and in the elderly. In the meta-analysis by Völtze et al. (11), only two prospective cohort studies $(7,9)$ were included. In these two studies, data pooling did not show an association between SHyper and circulatory mortality (pooled hazard ratio 0.95 and $95 \%$ confidence interval (CI) 0.52-1.74). The same two studies were included in the meta-analysis by Singh et al. (12) in which the pooled estimate of the relative risk of coronary artery disease at baseline and during follow-up, and the relative risk for mortality from cardiovascular causes were not significantly higher in patients with SHyper.

Several novel aspects emerge from the meta-analysis by Haentjens et al. (13) that appears in this issue of the European Journal of Endocrinology. Seven cohorts affected by SHyper were evaluated, and the results were compared with those of two previous meta-analyses $(11,12)$. The meta-analysis included the study by Parle et al. (8), and studies conducted in elderly patients (14) and in patients with co-morbidity conditions (15-17), such as patients affected by cardiac disease (15), patients recovering from stroke or hip replacement (16), and patients affected by diabetes mellitus (17) in which untreated SHyper had more harmful effects. The pooled hazard ratio for all-cause mortality was $1.41(95 \% \mathrm{CI}, 1.12-1.79 ; P=0.004)$ and the relative all-cause mortality was $40 \%$ higher in individuals with SHyper than in euthyroid subjects. The formal analysis based on the published survival curves available for five cohorts showed that the increased likelihood of death appeared 2 years after the diagnosis of SHyper and continued up to 10 years post diagnosis. Mathematical modeling suggested that absolute excess mortality after diagnosis might depend on age because it increased in patients over the age of 60; this was particularly evident in men. This finding argues strongly for a higher cardiovascular risk in elderly persons with SHyper, and supports the concept that treatment should be considered in this age group and in patients with associated cardiac disease or diabetes as well as in patients at high thromboembolic risk, i.e., patients recovering from stroke or hip fracture surgery. Indeed, SHyper was associated with an increased risk of osteoporosis and fractures in elderly subjects. Endogenous SHyper is more prevalent in the elderly and is common among patients 
with underlying heart disease in iodine-deficient areas. Therefore, the relationship between low serum TSH levels and increased mortality might be particularly important in iodine-deficient areas.

Treatment should certainly be considered in elderly SHyper patients with low or undetectable serum TSH, because of the increased cardiovascular risk in this age group; ablative therapy with ${ }^{131} \mathrm{I}$ is the preferred option for most patients, in the absence of a large goiter (18). Anticoagulation and antithyroid drugs should be administered before radioiodine in elderly subjects with atrial fibrillation to improve cardiac function and to reduce the thromboembolic risk (18). In young and middle-aged patients, especially those with undetectable serum TSH, the physician should look for associated cardiovascular risk factors (underlying heart disease, atrial fibrillation, left ventricular hypertrophy or associated co-morbidities) to establish the risk of the disease and to evaluate the potential beneficial effect of TSH normalization with radioiodine or surgery (18).

Also mild and subclinical hypothyroidism (SHypo) can be associated with important cardiovascular effects that could be responsible for the increased risk of atherosclerosis and coronary heart disease $(18,19)$. However, epidemiological studies of cardiovascular mortality and of the risk of atherosclerosis and coronary diseases have yielded discordant results. The risk of coronary disease was increased in SHypo in the crosssectional analysis in the Rotterdam study in women (20), in the cross-sectional analysis in the Nagasaki study in men (21) and in the cross-sectional and longitudinal analyses in the Busselton study in subjects with serum TSH levels of $10 \mathrm{mIU} / \mathrm{l}$ or less and greater than $10 \mathrm{mIU} / \mathrm{l}$ (9). On the contrary, mild SHypo and autoimmune thyroid disease were not associated with coronary heart disease in the studies by Cappola et al. (7), Rodondi et al. (22) and Vanderpump et al. (23).

SHypo-induced mortality was assessed in six studies and it was increased only in men in the longitudinal follow-up study by Imazumi et al. (21), whereas it was decreased only in the 4-year follow-up by Gussekloo et al. (14), which involved very elderly subjects. However, these two studies included selected populations affected by SHypo (i.e. atomic bomb survivors in the Nagasaki study and 85-year-old individuals in the Leiden study), thereby limiting generalization of the findings.

Several recent meta-analyses have evaluated the association of SHypo with all-cause and circulatory mortality. Not all possible relevant confounders for the association between SHypo and mortality were considered in each of the prospective cohort studies. Consequently, Völtze et al. (11) included only four studies in their meta-analysis $(7,9,21,22)$, and concluded that the evidence for a causal relationship between SHypo and mortality is weak and should not be used to decide whether or not to treat SHypo patients.

The meta-analysis by Haentjens et al. (13) included studies performed in SHypo patients with a specific associated disease, namely, cardiac patients (15), subjects with a history of stroke or hip replacement (16) and patients affected by diabetes mellitus (17). The pooled hazards ratio for all-cause mortality was 1.03 in cohorts from the community $(95 \%$ CI, $0.78-1.35$; $P=0.83)$, and 1.76 (95\% CI, 1.36-2.30; $P<0.001)$ in cohorts of participants with co-morbidities $(P=0.014$ for heterogeneity among study groups). The relative risk of all-cause mortality was increased in patients with a concomitant disorder. In particular, cardiac death for ischemic heart disease was significantly higher in elderly cardiac patients with SHypo than in euthyroid subjects. Interestingly, the risk of mortality associated with SHypo seems to be increased only in subjects below 65 years of age, whereas it seems to exert a protective effect in subjects over the age of 65 (18).

Replacement therapy with levothyroxine $\left(\mathrm{L}-\mathrm{T}_{4}\right)$ may improve cardiovascular function and may reverse the cardiovascular risk factors associated with SHypo (18). However, more randomized controlled trials and longitudinal studies are necessary to establish whether or not replacement therapy with $\mathrm{T}_{4}$ can improve cardiac morbidity and mortality. In the meantime, it seems advisable to consider $\mathrm{L}-\mathrm{T}_{4}$ replacement therapy in all patients with SHypo with TSH above $10 \mathrm{mIU} / \mathrm{l}$ and in selected patients with mild SHypo associated with a high cardiovascular risk background (i.e., patients with documented diastolic dysfunction, diastolic hypertension, atherosclerosis, dyslipidemia or diabetes mellitus, and smokers) with the aim of reducing the cardiovascular risk and the risk associated with co-morbidity (18). The detection of specific cardiovascular risk factors may help to identify high-risk patients who require immediate attention, and the cardiovascular risk may be reduced by appropriate intervention. Replacement treatment with $\mathrm{L}-\mathrm{T}_{4}$ should be individualized: the target TSH level of replacement therapy should be between 1 and $2.5 \mathrm{mIU} / \mathrm{l}$ in young and middle-aged patients, 3 and $4 \mathrm{mIU} / \mathrm{l}$ in individuals aged between 60 and 75 years, and 4 and $6 \mathrm{mIU} / \mathrm{l}$ in individuals older than 70 years (18).

\section{References}

1 Klein I \& Danzi S. Thyroid disease and the heart. Circulation 2007 116 1725-1735.

2 Gharib H, Tuttle RM, Baskin HJ, Fish LH, Singer PA \& McDermott MT. American Association of Clinical Endocrinologists; American Thyroid Association; The Endocrine Society Consensus Statement \#1: subclinical thyroid dysfunction: a joint statement on management from the American Association of Clinical Endocrinologists, the American Thyroid Association, and the Endocrine Society. Journal of Clinical Endocrinology and Metabolism $200590581-585$.

3 Surks MI, Ortiz E, Daniels GH, Sawin CT, Col NF, Cobin RH, Franklyn JA, Hershman JM, Burman KD, Denke MA, Gorman C, Cooper RS \& Weissman NJ. Subclinical thyroid disease: scientific review and guidelines for diagnosis and management. Journal of the American Medical Association 2004291 228-238. 
4 Biondi B, Palmieri EA, Klain M, Schlumberger M, Filetti S \& Lombardi G. Subclinical hyperthyroidism: clinical features and treatment options. European Journal of Endocrinology 2005152 $1-9$.

5 Biondi B, Palmieri EA, Lombardi G \& Fazio S. Effects of subclinical thyroid dysfunction on the heart. Annals of Internal Medicine 2002 137 904-914.

6 Dörr M, Empen K, Robinson D, Wallaschofski H, Felix S \& Volzke H. The association of thyroid function with carotid artery plaque burden and stroke in a population-based sample from a previously iodine-deficient area. European Journal of Endocrinology 2008159 145-152.

7 Cappola AR, Fried LP, Arnold AM, Danese MD, Kuller LH, Burke GL, Tracy RP \& Ladenson PW. Thyroid status, cardiovascular risk, and mortality in older adults. Journal of the American Medical Association 2006295 1033-1041.

8 Parle JV, Maisonneuve P, Sheppard MC, Boyle P \& Franklyn JA. Prediction of all-cause and cardiovascular mortality in elderly people from one low serum thyrotropin result: a 10-year cohort study. Lancet $20013 \mathbf{3 5 8} 861-865$.

9 Walsh JP, Bremner AP, Bulsara MK, O'Leary P, Leedman PJ, Feddema P \& Michelangeli V. Subclinical thyroid dysfunction as a risk factor for cardiovascular disease. Archives of Internal Medicine $20051652467-2472$.

10 Bauer DC, Rodondi N, Stone KL, Hillier TA \& Study of Osteoporotic Fractures Research Group: Universities of California (San Francisco), Pittsburgh, Minnesota (Minneapolis); Kaiser Permanente Center for Health Research, Portland. Thyroid hormone use, hyperthyroidism and mortality in older women. American Journal of Medicine $2007 \mathbf{1 2 0}$ 343-349.

11 Völzke H, Schwahn C, Wallaschofski H \& Dörr M. Review: the association of thyroid dysfunction with all-cause and circulatory mortality: is there a causal relationship? Journal of Clinical Endocrinology and Metabolism 200792 2421-2429.

12 Singh S, Duggal J, Molnar J, Maldonado F, Barsano CP \& Arora R. Impact of subclinical thyroid disorders on coronary heart disease, cardiovascular and all-cause mortality: a meta-analysis. International Journal of Cardiology $2008 \mathbf{1 2 5} 41-48$.

13 Haentjens P, Van Meerhaeghe A, Poppe K \& Velkeniers B. Subclinical thyroid dysfunction and mortality: an estimate of relative and absolute excess all-cause mortality based on timeto-event data from cohort studies. European Journal of Endocrinology 2008 (Epub ahead of print).
14 Gussekloo J, van Exel E, de Craen AJ, Meinders AE, Frolich M \& Westendorp RG. Thyroid status, disability and cognitive function, and survival in old age. Journal of the American Medical Association 2004292 2591-2599.

15 Iervasi G, Molinaro S, Landi P, Taddei MC, Galli E, Mariani F, L'Abbate A \& Pingitore A. Association between increased mortality and mild thyroid dysfunction in cardiac patients. Archives of Internal Medicine 2007 167 1526-1532.

16 Radácsi A, Kovács G, Bernard W, Feldkamp J, Horster FA \& Szabolcs I. Mortality rate of chronically ill geriatric patients with subnormal serum thyrotropin concentration: a 2-yr follow-up study. Endocrine 200321 133-136. Erratum in: Endocrine 2003 22341.

17 Chubb SA, Davis WA \& Davis TM. Subclinical hypothyroidism and mortality in women with type 2 diabetes. Clinical Endocrinology $2006 \mathbf{6 4} 476-477$.

18 Biondi B \& Cooper DS. The clinical significance of subclinical thyroid dysfunction. Endocrine Reviews 200829 76-131.

19 Biondi B. Cardiovascular effects of mild hypothyroidism. Thyroid 200717 625-630.

20 Hak AE, Pols HA, Visser TJ, Drexhage HA, Hofman A \& Witteman JC. Subclinical hypothyroidism is an independent risk factor for atherosclerosis and myocardial infarction in elderly women: the Rotterdam Study. Annals of Internal Medicine 2000132 270-278.

21 Imaizumi M, Akahoshi M, Ichimaru S, Nakashima E, Hida A, Soda M, Usa T, Ashizawa K, Yokoyama N, Maeda R, Nagataki S \& Eguchi K. Risk for ischemic heart disease and all-cause mortality in subclinical hypothyroidism. Journal of Clinical Endocrinology and Metabolism 200489 3365-3370.

22 Rodondi N, Newman AB, Vittinghoff E, de Rekeneire N, Satterfield S, Harris TB \& Bauer DC. Subclinical hypothyroidism and the risk of heart failure, other cardiovascular events, and death. Archives of Internal Medicine 2005165 2460-2466.

23 Vanderpump MP, Tunbridge WM, French JM, Appleton D, Bates D, Clark F, Grimley Evans J, Rodgers H, Tunbridge F \& Young ET. The development of ischemic heart disease in relation to autoimmune thyroid disease in a 20-year follow-up study of an English community. Thyroid $1996 \mathbf{6} 155-1560$.

Received 15 July 2008

Accepted 16 July 2008 